\title{
РАЗВИТИЕ НРАВСТВЕННЫХ ЧУВСТВ И ЭМОЦИЙ
}

\begin{abstract}
Аннотация. Данная статья посвящена вопросам развития нравственных чувств и эмоций у современного человека. Актуальность темы данной статьи определена тем фактом, что каждая личность имеет выраженный эмоциональный строй и стиль, разнообразие чувств, в которых она воспринимает мир. Люди в эмоциональном плане отличаются по: эмоциональной возбудимости, длительности и устойчивости эмоциональных перениваний; по доминированию положительных (стенических) или отрицательных (астенических) эмоций.

Таким образом, предметом исследования данной статьи является система бормирования и развития нравственных чувств и эмоиий, объектом - процесс формирования данных человеческих проявлений.

В процессе написания данной статьи был обобщен опыт различных исследователей в данном вопросе, по итогам которого были сделаны определенные выводы.

Практическая значимость статьи заключается в возможности использования сделанных автором статьи выводов на практике.

Ключевые слова: психология, чувства, эмоции, личность, взачмоотношения, взаимодействие, агрессия, психика, возбуждение, взачмосвязь.
\end{abstract}

Ч еловек не может быть абсолютно счастлив. В каждый отдельный момент своей жизни он чувствует себя или умеренно, или безмерно счастливым, то несчастным, то находящимся где-то посередине между крайними состояниями. В связи с этим можно выделить конкретные блоки, характеризующие личностный рост нравственных чувств каждого человека.

1. Блок личностного роста («справедливость - обида»). Чувство обиды возникает у человека, когда он считает, что по отношению к нему совершена какая-то несправедливость, имеет место обман, неблагодарность. В основе этого чувства лежит механизм неподтвержденного ожидания относительно значимых других. При этом формируются механизмы психологической защиты, препятствующие личностному развитию.

2. Блок взаимоотношений или межличностного взаимодействия («дружба - ссора»). Здесь рассматриваются коммуникативные эмоции, возникающие на основе потребности в общении, желании делиться переживаниями, найти отклик, чувства симпатии, расположения, уважения. Поэтому отношение «дружба - ссора» - очень важная психологическая информация об уровне развития личности.

3. Блок потенциальной агрессии («доброта - злоба»). Переживания, возникающие на основе потребности в содействии и доверии, желании приносить другим людям радость; сопереживание удачи и радости за другого, чувства участия и жалости.

Нравственные чувства позволяют не только понять мотивы другого человека, но и вызывают эмоциональную идентификацию. Нравственные чувства возникают и развиваются на основе потребностей личности, синтеза знаний и переживаний.

Укрепляясь, стабилизируясь в психике, чувство постепенно становится компонентом мотива поступка. А это означает переход чувства на высшую ступень, на которой оно, не утрачивая своей чувственной основы, тесно связывается, сплавляется с сознанием.

Устойчивое чувство начинает определенным образом влиять на поведение ребенка, становится мотивом поведения. Формирование конкретного морального чувства - это его постепенное становление, превращение из недифференцированной эмоциональной реакции в специфическое чувство. Первые эмоциональные реакции ребенка, проявляющиеся во взаимоотношениях с людьми, подражательны.

А.А. Люблинская ${ }^{1}$, поддерживая ту точку зрения, что нравственные чувства непосредственно проявля-

\footnotetext{
1 Люблинская А.А. О моральных представлениях и моральных привычках [Текст] / А.А. Люблинская // Психология дошкольника: хрестоматия / сост. Г.А. Урунтаева. М.: Академия, 1998. С. 296-302.
} 


\section{Спектр эмоциональных переживаний}

ются и укрепляются в наблюдении за конкретными действиями и поступками человека, считает, что, если нет органической связи знаний (моральных понятий), оценочного отношения (хорошо - плохо) и поступка, ни о каком нравственном воспитании личности говорить не приходится.

Нравственнье чувства развиваются только на основе знаний, постепенного освоения нравственных понятий, оценок. В моральном чувстве к себе (стыд) ребенок анализирует и переживает недоброе, негативное, требующее исправления. В моральном чувстве к другим людям (альтруизм) чувствует притяжение к ним, сострадание, желание доставить радость.

В зарубежной психологии выдвигались различные теории развития моральных чувств. Одни авторы (В. Штерн, К. Бюллер) считали их врожденными, предопределенными наследственностью. Другие (например, психоаналитики), по существу, отрицали специфичность моральных переживаний и полагали, что нравственные чувства ребенка являются завуалированными формами проявления его асоциальных, биологических влечений.

В противоположность этим биологизаторским концепциям, советские психологи считают, что в процессе развития ребенка определенные нравственные чувства постепенно формируются у него при решающем влиянии социальных условий его жизни и воспитания.

Появление чувств имеет своим источником реальный мир, существующий независимо от человека, с которым человек вступает в многообразные связи и отношения. В процессе взаимодействия с окружающей средой у него могут возникать ответные реакции на полученные воздействия.

Чувство, как напряжение организма, возбуждение, находит свою реализацию и разрядку: или внешне выражается в каких-то действиях, или изменяет внутренние установки человека, его отношение к некоторым людям, объектам. Может задержаться и найти выход через промежуток времени. Чувства надо воспитывать.

Возникновение у человека определенного конкретного чувства определяется характером взаимосвязи, которая существует между человеком и окружающей его действительностью. Новые изменения в обстоятельствах жизни человека познаются и оцениваются им. Это приводит к изменениям в содержании переживаемого чувства. Динамика чувства в процессе переживания, вызванная изменениями ситуации, будет различной в зависимости от глубины чувства.

Характерная особенность чувств заключается в том, что причины, вызывающие их, ясны для переживающей личности. Элемент познания обязателен для возникновения чувств, как и переживание, эмоциональная реакция. Чувство может выступать в сознании человека в других формах: может быть не полностью осознанным и выражаться тогда, как невольная антипатия, «интерес», «направленность» на объект «уклонение от объекта.

В отечественной психологии данная точка зрения была высказана Н.Н. Лицевой, Р.Л. Кричевским, Е.В. Васиной, Е.Е. Насиновской и другими.

В.В. Абраменкова отмечает, что с развитием рефлексии под руководством взрослого у ребенка развивается способность ставить себя на место другого, воображать себя в роли другого, соотносить свои действия с действиями другого, иными словами, развиваете и способность ребенка к интерперсональному отождествлению ${ }^{2}$.

Понятие «солидарная идентификация», введенное В.В. Абраменковой, характеризуется, проявляется совместная ответственность каждого в группе за успехи и неудачи в деятельности. При этом совместная деятельность детей осуществляется ради другого человека, сверстника, который способен приобрести для каждого из группы личностный смысл.

Здесь идентификация развивает у ребенка способность не просто ставить себя на чести другого, относясь к себе как бы со стороны, но и соотносить свое поведение с морально-этическими нормами, исходящими от взрослых 3 . В соответствии с нормами осуществляется принятие решении и «проигрывание» собственного действия в воображаемом плане.

Эмоции - особый класс субъективных психологических состояний, отражающихся в форме непосредственных переживаний, ощущения приятного или неприятного, процесс и результаты его практической деятельности. Это физиологический и социальный процесс. По эмоциям определяется, что волнует личность, какие интересы являются для неё самыми актуальными. Их природа эволюционная.

Эмоции (возбуждать, волновать) - состояния, связанные с оценкой значимости для индивида действующих на него факторов и выражающихся в форме непосредственных переживаний удовлетворения или неудовлетворения его актуальных потребностей. Они - главный регулятор деятельности ребенка и взрослого.

П.В. Симонов считает, что эмоциональные состояния могут быть хорошими и плохими (настроение), полезными и вредными (боль), положительными и отрицательными (радость, страх). Они характеризуются: оценкой отражение содержания: хорошо - плохо; побуждением, активацией - мобилизацией силы организма.

\footnotetext{
2 Абраменкова В.В. Генезис отношений ребёнка в социальной психологии детства [Текст]: дис. ... д-ра психол. наук / В.В. Абраменкова. М., 2000. 420 с.

3 Там же.
} 


\section{Психология и психотехника 1(52) • 2013}

В концепции П.В. Симонова понимание проявления эмоций есть механизм дефицита информации (информационная теория). Он определяет эмоции как «отражение мозгом человека актуальной потребности и вероятности её удовлетворения, которую мозг оценивает на основе генетического и ранее приобретённого индивидуального опыта. Доказывая связь эмоциональных отношений с социальными нормативами, он подчёркивает их неизменность.

В концепции П.К. Анохина, эмоция - адаптационный механизм приспособления психики к окружающей среде. Согласно ему, эмоциональные состояния организма имеют ярко выраженную субъективную окраску и являются переживаниями от радости до страданий.

Воспринимая переживания персонажа, выраженные в мимике, дошкольники легче схватывают мимику радости и гнева. Характерной чертой эмоций ребенка является их живость, яркость и легкая возбудимость. Ребенок легко заражается настроением окружающих, у него происходит быстрая и резкая смена эмоций: можно наблюдать, как заплакавший маленький ребенок через несколько минут уже смеется.

Для переживания и умения проявлять адекватные реакции на чужие эмоции ребенку нужен опыт совместного проживания своих эмоций и эмоций партнера по общению при различных по характеру эмоциональных воздействиях.

Экспериментальные исследования А.В. Запорожца и анализ практики показывают, что словесные указания могут стать эффективными лишь тогда, когда они включаются в практическую деятельность ребенка. Об этом свидетельствуют проявления детьми сочувствия страха, радости или переживаний в соответствии сэкспрессивной картиной поведения близкого им человека ${ }^{4}$.

A.В. Запорожец утверждал, что эмоции выполняют функцию ориентировки в личностных смыслах, которые имеют для него предметы окружающего мира, новых мотивов поведения, превращая их из знакомых в реально действующие, и в реализации имеющихся у субъекта мотивов поведения, где проявляется регулятивно-побудительная функция эмоций. Когнитивные процессы должны служить фактором контроля и замещения эмоций. Они могут мгновенно объединять в единое целое деятельность разных функций организма и быстро давать ответную реакцию.

В структуре эмоций есть компонент эмоционального возбуждения, определяющий мобилизационные сдвиги в организме. Он обозначает значение эмоциогенного события для субъекта: позитивность или негативность. В этом есть знак эмоций.

\footnotetext{
4 Там же.
}

Положительная эмоция возникает, если событие оценивается позитивно и наоборот. Механизм отрицательных эмоций функционирует у ребенка с первого дня появления его на свет, а положительные эмоции появляются значительно позже.

Отрицательные эмоции вредны в избытке, как вредно все, что превышает норму, характеризующую то, в чем организм непосредственно нуждается. Они выполняют более важную биологическую функцию по сравнению с положительными эмоциями.

Характерной чертой эмоций ребенка является их живость, яркость и легкая возбудимость. Ребеноклегко заражается настроением окружающих, у него происходит быстрая и резкая смена эмоций: можно наблюдать, как заплакавший маленький ребенок через несколько минут уже смеется.

Для переживания и умения проявлять адекватные реакции на чужие эмоции ребенку нужен опыт совместного проживания своих эмоций и эмоций партнера по общению при различных по характеру эмоциональных воздействиях. Первые эмоциональные реакции ребенка, проявляющиеся во взаимоотношениях с людьми, подражательны. Он понимает непосредственное значение событий, позднее - их обобщенный смысл.

С возрастом у ребенка развиваются умение регулировать проявление своих чувств и управлять ими. У них появляются скрываемые чувства. В силу этого по-иному выступает старая этическая категория «добро» - как содержание самой жизни, как его деятельность. Б.И. Додонов утверждает, что устойчивая потребность человека в благе другого отражается в тенденции к переживаниям альтруистических эмоций.

Если эта потребность не удовлетворена, человек испытывает тягостное состояние. Эмоции как внешнее проявление внутреннего мира ребенка позволяют определить его отношения к происходящему, способствуют личностному становлению.

Аффективный (эмоционально-мотивационный) компонент проявляется в разнообразных эмоциональных состояниях и реакциях, которые фиксируются в виде положительных и отрицательных эмоций, эмоциональной чувствительности, конфликтности.

Эмоция, возникающая вследствие сопереживания, способна «переключиться» на предмет-причину и своим развитием обеспечивать сходное эмоциональное восприятие людьми явлений внешнего мира.

В процессе удовлетворения потребностей субъекта эмоциональные явления распадаются на две фундаментальные группы. Одну из них составляют переживания, окрашивающие предметы потребностей и превращающие их в мотивы. Для возникновения этих переживаний достаточно обострения некоторой потребности и наличия отвечающего ей предмета. 


\section{Спектр эмоциональных переживаний}

Е.П. Ильин, Н.Д. Левитов, А.О. Прохоров и др. отмечают важность в структуре психологии эмоций эмоцииональнье состояния, которые подразделяются на стенические, астенические и амбивалентные. Они многообразны по содержанию, динамике, но слабо изучены как категория в психологии состояний. В них ярко выражена субъективная сторона переживаний от радости до состраданий. На них влияют меняющиеся факторы.

На смену астеническим эмоциональным состояниям приходят стенические, и тогда ведущими становятся амбивалентные состояния, что преобразовывает все поведение человека. Стенические состояния побуждают к активной деятельности и мобилизуют силы. Высокий уровень социальной ориентации обнаруживается у детей с эмоциональным типом поведения, в отличие от рационального или индифферентного типа.

Под эмоциональным состоянием нужно понимать временный определенный функциональный уровень коры больших полушарий. С физиологической точки зрения эмоциональные состояния - это протекающий на одном уровне процесс возбуждения или торможения, или их мозаика, в пределах одной какой-либо анализаторной системы или коры в целом.

К ним мы относим определенные психические состояния человека. Они, по мнению В.Н. Мясищева, представляют собой одну из важнейших составляющих психики человека, на них влияет его физическое состояние. Психические состояния, всегда детерминированные извне или изнутри, зависят от индивидуальных особенностей человека и его предшествующих состояний.

Они является переживанием и деятельностью, имеющей внешнее выражение, могут быть продолжительными или краткими, более и менее осознанными. Н.Д. Левитов определяет их, как относительно устойчивое явление психической деятельности, характеризующее психику в целом.

Он выделяет личностные, более глубокие (выражение индивидуальных свойств человека, вызывающие у человека нетипичные для него реакции) и ситуативные (поверхностные в зависимости от силы их влияния на переживания и поведение человека). Л. Колберг утверждал, что в психическом развитии происходит не только формирование знаний об окружающем мире, о нравственной природе, но идет эмоциональное развитие, характеризующее собой переживания. У. Джемс рассматривал психические состояния исключительно в интроспективном плане, основываясь на внутреннем опыте, субъективных данных сознания.

В. Вундт предпринял попытку объединить эмоциональные состояния по общим признакам в компактную систему. Ориентироваться на другого - значит уметь определить его эмоциональное состояние, проявить со - чувствие, оказать со - действие. Например, отзывчивость состоит в способности эмоционально реагировать на то, что волнует людей, если затронуты задачи, цели, которыми живут люди. На положительные ситуации будет один эмоциональный отклик, а на отрицательные - другой.

Апатия может служить примером отрицательного эмоционального состояния, а вдохновение - состояние, положительно влияющее на деятельность человека. Физиологической основой положительных состояний является процесс возбуждения, отрицательных - процесс торможения. Воспитание чувств - сложный процесс. Для дошкольников характерна слитность высших чувств. Один и тот же объект может вызывать переживание, в котором слиты эстетические, этические и познавательные чувства. Развитие чувств ребёнка связано с формированием интеллекта, его мыслительных способностей, знаний о положительно и отрицательно оцениваемых образцах поведения. Благодаря чему он получает возможность оценивать характер своей деятельности, предвидеть и подготовиться к восприятию предстоящей оценки своего поведения со стороны присутствующих.

А.А. Люблинская, утверждает, что нравственные чувства ребёнка проявляются и укрепляются в наблюдениях за конкретными действиями и поступками человека, что, если нет органической связи знаний (моральных понятий), оценочного отношения (хорошо плохо) поступка, ни о каком нравственном воспитании личности говорить не приходится ${ }^{5}$.

Нравственные чувства вызывают эмоциональную идентификацию. Чувства ребенка-дошкольника становятся более глубокими. Это связано с нарастающим социальным опытом ребенка. Дети могут оценить поступок другого с позиции общепринятых норм поведения и дать какое-то обобщенное суждение о том, что они услышали и увидели.

В научных исследованиях Л.С. Выготского, А.В. Запорожца, А.Н. Леонтьева, Д.Б. Эльконина проблема развития нравственных чувств личности занимает значительное место. Умение владеть своими чувствами психологически означает умение владеть внешним выражением.

Чувства общественно и исторически обусловлены, как сама человеческая личность, изменяющаяся с развитием общества. Они возникают как выражение его отношения к соответствующему поступку и в процессе взаимоотношений с окружающими людьми. Эмоции составляют форму переживания чувств.

Люблинская А.А. О моральных представлениях и моральных привычках [Текст] / А.А. Люблинская // Психология дошкольника: хрестоматия / сост. Г.А. Урунтаева. М.: Академия, 1998. С. 296-302. 


\section{Психология и психотехника 1(52) • 2013}

Физиологический механизм чувств, как составляет система временных связей, отражающая определенную систему взаимоотношений индивида с окружающей средой. Образование, установка и переделка временных связей и есть те процессы, которые лежат в основе образования и проявления положительных и отрицательных чувств во всей их сложности.

И.П. Павлов показал, что различные виды чувств, испытываемые сразличной степенью интенсивности, возникают на основе работы коры больших полушарий. «Чувства, как и мысли человека, возникают в деятельности мозга, но любит и ненавидит, познает и изменяет мир не мозг, а человек» ${ }^{6}$.

Чувства - это то, что значит один индивид для другого, каждое из них по определению индивидуально. Предметами чувств являются явления и условия, от которых зависит развитие событий, значимых для личности и поэтому воспринимаемых эмоционально.

В работах Л.С. Выготского, А.Н. Леонтьева, Д.Б.Эльконина подчеркивается, что формирование высших человеческих чувств идет в процессеусвоения ребенком социальных ценностей, требований, норм и идеалов, которые при определенных условиях становятся внутренним достоянием личности, содержанием побудительных мотивов ее поведения. Основанные на самооценке и самоанализе устойчивые нравственные чувства формируют обобщенно устойчиво-эмоциональные отношения к личности в целом. Это - интимная сфера человеческой психики, и всякое воздействие на эту сферу требует особого подхода.

Нравственные чувства развиваются на основе знаний и освоения нравственных понятий и оценок.

Справедливость, честь, долг, ответственность, патриотизм, любовь, благородство, гордость, уважение - это нравственно положительные чувства.

Существуют и негативные чувства (аморальные) по отношению к другим людям: огорчение, тревога, страх, сожаление, досада, обида, чувство оскорбления, неуверенность, растерянность, смущение, стыд, угрызения совести. Они как моральные регуляторы, заставляющие стать другим человеком. Под их влиянием происходит регуляция поступков, действий, желаний, сообразно установленным этическим требованиям общества.

Психологи утверждают, что нравственные чувства не могут возникнуть путем естественного вызревания. Их развитие зависит от условий, в которых живет личность. Существенной стороной в развитии нравственных чувств является рост их понимания переживаний других людей и умение «сопереживать» сними то, что их волнует, печалит.

Чувства - это ориентации, основанные на персонификациях, которые конструируются главным

6 Павлов И.П. Избранные произведения [Текст] / И.П. Павлов. М.: Изд-во АН СССР, 1949. 546 с. образом путем приписывания мотивов. Приписать мотив - значит сделать заключение о внутренних переживаниях другого человека.

Чувства рождаются вместе с социальным опытом, так как всякий социально-психический опыт выражается в чувствах. Чувство может выступать в сознании человека в двух формах. Оно может быть не полностью осознанным и выражаться как «симпатия» (антипатия), «интерес», «направленность» на объект («уклонение» от объекта).

Соответственно оно проявляется и в особенностях поведения человека. В современной психологии отражены два взгляда на вопрос об эволюции чувств: первый - ассоциативная теория.

Согласно этой теории, развитой психологом Геффдингом, существует лишь два основных чувства - удовольствие и страдание, а все остальные чувства возникают из ассоциации этих чувств с теми или иными образами. Второй - органическая теория эволюции чувств. Согласно ей, невозможно сводить все чувства к двум основным: мир чувств также взаимонесводим, как с психологической точки зрения надо говорить о цветах, о тембрах.

Чувства порождаются потребностями человека и способностью отразить и понять определенные свойства объекта. Они являются положительной ценностью, которая определяется тем, к каким отношениям человек стремится. Чувства совершенствуются и, развиваясь, образуют ряд уровней: от непосредственных чувств до высших, относящихся к духовным ценностям и идеалам.

Важным качеством чувств является их объединения и подчинения себе разных состояний и реакций. Моральными называют те чувства, «на дне» которых, при их развитии, оказывается «моральная идея». Они являются формой, в которой выступает моральный опыт. С возрастом у ребенка проявляются скрываемые чувства.

В силу этого старая этическая категория «добро» выступает не только в аспекте характера отношения к другим людям, но и как содержание самой жизни человека, как его деятельность. У семилетнего ребенка воспитаны разнообразные чувства, интересы, желания. Он испытывает сложные и порой противоречивые чувства и переживания.

По мнению Р.С. Немова, переживание - это ощущение, сопровождаемое эмоциями. Возникая как результат обобщения эмоционального опыта, сформировавшиеся чувства становятся ведущими образованиями эмоциональной сферы человека и начинают определять динамику и содержание ситуативных эмоций.

Характеризуя чувства, В.В. Зеньковский ${ }^{7}$ их классифицирует на: индивидуальные: страх, гнев, чувства к

\footnotetext{
Зеньковский В.В. Психология детства [Текст] / В.В. Зеньковский. М.: Академия, 1996. 347 с.
} 


\section{Спектр эмоциональных переживаний}

самому себе, стыд; социальные (межиндивидуальные): социальный стыд, симпатия и антипатия, сексуальные переживания; высшие (надындивидуальные): моральное, эстетическое и религиозное чувство.

Чувства могут проявляться в отношении ребенка к себе (чувство собственного достоинства или чувство неполноценности, уверенность или отчаяние), и в отношении к другим людям (симпатия или антипатия, сочувствие, злоба, гнев, безразличие, чувство дружбы, любви).

Сильным стимулятором в этом является механизм поощрения, получение награды. Слабое стимулирующее воздействие оказывает механизм наказания. Самым слабым воздействием на принимаемые ребенком решения обладает механизм прямого запрещения действий, не подкрепленное другими дополнительными мотиваторами.

А.А. Гусейнов приходит к заключению, что нравственные добродетели признаются основой для нравственного поведения. Для формирования чувств ребенка, его нормального развития значение имеет воспитание эмоционально-положительного отношения к окружающему. В итоге у ребенка появляется оценочное суждение о собственном поведении «я вел себя хорошо», «своим поступком я огорчил маму».

Ребенок должен усвоить форму (знания в области нравственности, внешнее соблюдение нравственных требований) и отношения, возникающие между людьми (их внутренний смысл, мотивы). Сначала он приобретает знания о нравственных нормах, которые при условии его воспитания, становятся мотивами поведения.

Ощущая на себе доброту, ребенок сам начинает относиться к себе как к доброму, нравственному человеку. У него возникает нравственная самооценка, которая будет характеризовать мотив подлинно нравственного поведения.

В результате усвоения нравственных норм и чувств ребенок приобретает своеобразную систему мер, эталонов ценности, сопоставляясь с которыми наблюдаемые явления оцениваются эмоционально как привлекательные или отталкивающие, добрые или злые, красивые или безобразные.

И.П. Павлов отметил, что одним из физиологических фундаментов чувств являются механизмы динамических стереотипов, которые образованы при жизни системой временных связей. Здесь возникают чувства тяжести и легкости, бодрости и уставшей, удовольствия и неприятности, радости, торжества и отчаяния. Часто такие чувства при изменении обычного образа жизни, при прекращении обычных занятий, потере близких имеют свою физиологическую подпочву в значительной мере в изменении, а нарушение старого динамического стереотипа и в сложности становления нового ${ }^{8}$.

\section{Список литературь:}

1. Абраменкова В.В. Генезис отношений ребёнка в социальной психологии детства [Текст]: дис. ... д-ра психол. наук / В.В. Абраменкова. М., 2000. 420 с.

2. Запорожец А.В. Игра и её роль в развитии ребенка дошкольного возраста [Текст] / А.В. Запорожец // Хрестоматия по возрастной психологии. М.: Изд-во Московского психолого-социального института; Воронеж: Изд-во НПО «Модэк», 2003. С. 203-207.

3. Зеньковский В.В. Психология детства [Текст] / В.В. Зеньковский. М.: Академия, 1996. 347 с.

4. Люблинская А.А. О моральных представлениях и моральных привычках [Текст] / А.А. Люблинская // Психология дошкольника: хрестоматия / сост. Г.А. Урунтаева. М.: Академия, 1998. С. 296-302.

5. Павлов И.П. Избранные произведения [Текст] / И.П. Павлов. М.: Изд-во АН СССР, 1949. 546 с.

\section{References (transliteration):}

1. Abramenkova V.V. Genezis otnosheniy rebenka v sotsial'noy psikhologii detstva [Tekst]: dis. ... d-ra psikhol. nauk / V.V. Abramenkova. M., 2000. 420 s.

2. Zaporozhets A.V. Igra i ee rol'v razvitii rebenka doshkol'nogo vozrasta [Tekst] / A.V. Zaporozhets // Khrestomatiya po vozrastnoy psikhologii. M.: Izd-vo Moskovskogo psikhologo-sotsial'nogo instituta; Voronezh: Izd-vo NPO «Modek», 2003. S. 203-207.

3. Zen'kovskiy V.V. Psikhologiya detstva [Tekst] / V.V. Zen’kovskiy. M.: Akademiya, 1996. 347 s.

4. Lyublinskaya A.A. O moral'nykh predstavleniyakh i moral'nykh privychkakh [Tekst] / A.A. Lyublinskaya // Psikhologiya doshkol'nika: khrestomatiya / sost. G.A. Uruntaeva. M.: Akademiya, 1998. S. 296-302.

5. Pavlov I.P. Izbrannye proizvedeniya [Tekst] / I.P. Pavlov. M.: Izd-vo AN SSSR, 1949. 546 s.

8 Павлов И.П. Избранные произведения [Текст] / И.П. Павлов. М.: Изд-во АН СССР, 1949. 546 с. 